\title{
Desafios e caminhos epistemológicos na abordagem do turismo a partir dos estudos da literatura e da cultura
}

\author{
Cristina Martínez Tejero \\ Universidade de Lisboa - Centro de Estudos Comparatistas
}

Resumo: A capacidade tentacular e o caráter omnívoro das práticas turísticas promoveram a sua expansão até praticamente qualquer área, tema ou território, incluindo entre eles a literatura, como demonstra o apogeu recente do turismo literário, nas suas diversas concretizações. As interseções que, atualmente, se produzem entre literatura e cultura e o turismo exigem novas abordagens analíticas e leituras críticas renovadas. Este estudo pretende precisamente reavaliar os motivos e as formas de estudar estes cruzamentos. Para tal, são fixados, em primeiro lugar, alguns traços significativos da prática turística na contemporaneidade, assim como os debates existentes no âmbito académico sobre a natureza deste fenómeno ou sobre a sua inter-relação com a cultura e com as identidades (locais, regionais e nacionais). Em segundo lugar, pretende-se discutir a necessidade de analisar o turismo a partir dos estudos da literatura e da cultura e propor algumas linhas de trabalho que podem ser relevantes nesta orientação, tais como a sua proximidade com a ideia de cânone, o papel dos produtos literários e culturais na construção de imaginários turísticos ou a sua (des)conexão com a literatura de viagens.

Palavras-chave: literatura, cultura, turismo, identidade, espaço, globalização

\begin{abstract}
The tentacular capacity and omnivorous character of tourism have promoted its expansion to almost any area, theme or territory, including literature, as the emergence of literary tourism (in its various forms) shows. The intersections between literature and culture with tourism demand new analytical approaches and renewed critical readings. The aim of this paper is to re-evaluate the reasons and ways to study these connections. To this end, some significant features of current tourist practice are set out, as well as the ongoing academic debates about the nature of this phenomenon or about its interrelationship with
\end{abstract}


culture and with identities (in a local, regional or national level). Secondly, I intend to explore the reasons for analyzing tourism in literature and culture studies and to offer some lines of research that may be relevant in this orientation, such as its proximity to the idea of canon, the role of literary and cultural products in the construction of tourist imaginaries or its (dis)connection with travel literature.

Keywords: literature, culture, tourism, identity, space, globalization

Este trabalho pretende debruçar-se sobre um elemento que podemos qualificar como incómodo no contexto dos estudos da literatura e da cultura: o turismo. ${ }^{1}$ Apesar desta avaliação global, há diversas correntes no âmbito académico que procuram aprofundar na relação (complexa) entre turismo e literatura. Estes estudos são realizados muitas vezes sob uma ótica pró-ativa, isto é, pretendem contribuir, de certa forma, para a implementação do turismo literário, o que deve ser lido segundo as coordenadas que procuram novas utilidades para a literatura no meio da crise das humanidades e também à luz das novas modalidades de turismo cultural.

Não é esta a posição defendida neste artigo que pretende oferecer uma visão diferente sobre os motivos para estudar as relações entre literatura e turismo. Para isto, tentarei, em primeiro lugar, estabelecer alguns traços significativos do turismo a partir de uma leitura cultural, com particular atenção aos contributos da geografia cultural, da sociologia ou da antropologia do turismo. Em segundo lugar, pretendo discutir a necessidade de estudar o turismo a partir da literatura - ou na sua interseção com a literatura - e sugerir algumas linhas de trabalho que podem ser relevantes nesta orientação.

\section{1. (In)definições do turismo}

O turismo é um dos fenómenos mais representativos da atualidade, incorporando e evidenciando na sua natureza o consumismo, a deslocação, a fugacidade ou a superficialidade. Neste sentido, torna-se um exemplo da modernidade líquida formulada por Bauman (2000) e um dos fenómenos que mais evidencia as lógicas da globalização. 
Trata-se de uma prática extremamente complexa, sobre a qual não existe uma definição clara: "Tourism is not a monolith. It is an exceedingly large-scale and diverse industry, operating in a variety of ways under differing circumstances" (Greenwood 1977: 129). Alguns dos traços que costumam ser considerados para a sua fixação são: a deslocação, a quebra da rotina, a sua associação ao lazer, ao prazer ou ao consumo, o seu caráter temporalmente limitado, etc.

Cada um destes aspetos levanta múltiplas questões que é impossível abordar com detalhe nestas páginas. Destacarei, por isso, apenas alguns elementos que lançam luz a este respeito. Em primeiro lugar, o sociólogo Zygmunt Bauman (1998) aponta que vivemos na era da compressão tempo-espaço e que estamos todas e todos em movimento, mesmo de modo involuntário: "Nowadays we are all on the move" (1998: 77). Esta ênfase na mobilidade é também salientada por Greenwood: "tourism is the largest scale movement of goods, services, and people that humanity has perhaps ever seen" (1977: 129). Porém, nem todas as pessoas têm as mesmas facilidades e direitos de mobilidade e aqui surgem as assimetrias entre as elites e as classes baixas, entre o primeiro e o segundo mundo, ou entre o turista e o migrante: "In the post-space-war world, mobility has become the most powerful and most coveted stratifying factor" (Bauman 1998: 9; veja-se também idem: 89). 0 turismo tem, portanto, uma dimensão física fundamental, estando vinculado a espaços concretos e sendo protagonizado (ou co-protagonizado) por corpos em movimento. ${ }^{2}$ Este fenómeno utiliza, aliás, um tratamento extensivo do corpo e do prazer que incorpora variáveis de um alto grau de violência - simbólica e material - articuladas em torno às divisões de género, classe e etnia. Não é alheio a isto o facto de vários estudiosos terem aludido às dimensões neocoloniais da prática turística (d'Hauteserre 2004; Hall / Tucker 2004). Com efeito, como assinala Greenwood (1977: 129), o desenvolvimento turístico tende a produzir desigualdades.

Este estudo foi iniciado com uma referência à incomodidade do turismo dentro das humanidades; esta reflexão deve, no entanto, ser igualmente considerada para as ciências sociais. De facto, houve e há, em geral, uma simpatia académica a favor da figura do viajante e em detrimento do turista (Crang 2004: 81), o que pode ser associado com a própria 
origem negativa do conceito de turista, destinado às classes trabalhadoras do Reino Unido que começaram a fazer viagens de lazer no século XIX (Smith 2004: 25 e s.), e oposto à figura do viajante, associado às classes altas. As dificuldades para analisar o turismo a partir dos estudos literários e da cultura devem ser igualmente lidas à luz das reflexões de Bourdieu sobre a aura atribuída à literatura e a incomodidade em abordar assuntos económicos nos campos culturais, onde o habitus exige uma lógica regida pelo interesse no desinteresse (Bourdieu 1992: 201 e ss.).

Por outro lado, com a sua raiz de natureza consumista, o turismo relaciona-se com processos de distinção social através do consumo e do gosto (Bourdieu 1979). Deste ponto de vista, Urry (2002) distingue entre o "collective tourist gaze" e o "romantic tourist gaze", o primeiro dos quais contemplaria práticas turísticas realizadas de forma coletiva, em convívio, e que só fazem sentido desta forma (por exemplo, festividades como o carnaval ou os parques temáticos); enquanto o segundo estaria dominado pela prática individual e pretensamente afastada das massas: "the romantic gaze, which is much more obviously auratic, concerned with the more elitist - and solitary - appreciation of magnificent scenery, an appreciation which requires considerable cultural capital especially if particular physical objects signify specific literary texts" (Urry 2002: 78). ${ }^{3}$

\section{0 turismo e a ficcionalização da realidade}

Existem vários debates ativos e relevantes em torno do turismo e que, simplificando, podem ser sintetizados nas controvérsias sobre a sua existência e grau de independência, por um lado, e nas tensões entre a autenticidade e a encenação, por outro. Em relação ao primeiro, a noção de turismo continua aberta e existe uma grande diversidade de opiniões sobre se pode, por exemplo, ser definido como uma indústria ou inclusive sobre a sua própria utilidade/viabilidade como conceito. ${ }^{4}$ Neste sentido, deparamos com uma contradição ambivalente na progressiva institucionalização dos estudos turísticos face às dificuldades para tornar consensual uma definição deste fenómeno.

Por outro lado, um elemento-chave do turismo reside na ideia da autenticidade e a sua tensão com a ficcionalização ou encenação. Um dos aspetos mais discutidos nas 
abordagens da sociologia ou da antropologia sobre o turismo é a ideia de autenticidade como um valor procurado pelos visitantes e que se concretizaria na busca e maior apreciação dos elementos considerados genuínos da cultura local (MacCannel 1999: 96 e ss.). ${ }^{5}$ Não obstante, há sempre uma manipulação - seja em maior ou menor grau - nos objetos e performances turísticas oferecidas, quer seja pela sua adaptação a um público alheio e a lógicas de mercado, ou simplesmente pelo facto de serem elementos retirados do seu contexto original. Tal resulta em reflexões conectadas com a ideia de hiper-realidade desenvolvida, entre outros, por Baudrilland (1981) ou Umberto Eco (1986). ${ }^{6}$ Deste ponto de vista, o antropólogo Marc Augé (1998 [1997]) refere que a dimensão ficcional tem cada vez mais peso no mundo atual, sobretudo através dos produtos turísticos, e sublinha a progressiva indistinção entre realidade e ficção (idem: 58). Invertendo a lógica prévia, a realidade acaba por imitar a ficção (idem: 57), o que resulta na "sustitución de los lugares de vida por un decorado (o si se quiere: sustitución de la vida real por la ciudad virtual)" (idem: 153).

Há uma ideia fundamental que resulta disto: qualquer elemento (material ou imaterial) é suscetível de ser tornado objeto de atração turística. ${ }^{7}$ Para este efeito, produzse sobre ele a construção de uma narrativa adoçada com estímulos que possam induzir à curiosidade das/dos visitantes. Isto é, há uma mediação, uma seleção de elementos que são destacados ou construídos (ou reconstruídos), enquanto outros são deliberadamente ignorados. 0 turismo apropria-se, portanto, de realidades, sejam estas pessoas, objetos ou espaços.

Porém, estes dois debates sobre a essência do turismo e sobre a questão da (in)autenticidade devem ser lidos à luz das novas reflexões desenvolvidas sob a ideia do pós-turismo, que pretendem colocar em evidência as alterações operadas sobre este fenómeno nas últimas décadas. Segundo esta proposta, os turistas atuais situam-se num espaço de jogo e prazer, onde a ideia de autenticidade perde sentido ou já não está presente. Simultaneamente, não é precisa a viagem para atuar como turista - é possível fazê-lo através dos meios tecnológicos ou a nível local - e funciona uma indistinção no consumo entre alta cultura e popular (Urry 2002: 78). 
Esta leitura leva-nos a uma proposta formulada pelo próprio Urry (idem: 161) que consiste no fim do turismo. Partindo de Guy Debord e das suas ideias sobre a sociedade do espetáculo (Debord 1992 [1967]), ${ }^{8}$ este autor assinala como os lugares turísticos estão hoje por todo o lado e simultaneamente os lugares quotidianos são redesenhados "em modo turista", mediante a criação de ambientes temáticos. ${ }^{9}$ Produz-se, portanto, uma quebra entre espaços e discursos que já não são exclusivamente dirigidos nem consumidos por visitantes. Nesta perspetiva, atrevo-me a apresentar uma proposta que vai além da enunciada por Urry e que consiste na afirmação da inexistência do turismo, ou seja, na ideia de que existem práticas turísticas, mas o turismo per se é apenas um sintoma ou caraterística da sociedade hiper-consumista atual e não propriamente uma atividade social independente.

\section{Práticas turísticas e fluxos culturais}

Pela sua própria natureza, o turismo evidencia os fluxos culturais da contemporaneidade, caracterizados por processos de estereotipação, simplificação e mercantilização, e onde os significados mudam e são reformulados de forma constante: “To practice and to perform are components of the flow of contemporary culture. Meanings change and are changed" (Crouch 2002: 91). A diferença do que acontecia em fases anteriores, estruturadas em torno da produção material, no capitalismo pós-fordista são especialmente relevantes as práticas económicas associadas à cultura e à criatividade, entre as quais o turismo é um exemplo privilegiado. Foram anteriormente referidos os processos de simplificação, mas devemos considerar simultaneamente leituras complexas, fenómenos de hibridação - segundo as propostas do geógrafo Mike Crang (2002) ou do antropólogo Néstor García Canclini (2001 [1989]) - que originam formas culturais que ultrapassam o dualismo local versus turístico. ${ }^{10}$

Tanto investigadoras/es procedentes da área da geografia cultural, como doutros campos do saber, têm insistido na necessidade de uma tomada de consciência do processo de transformação em mercadorias dos lugares e culturas na economia contemporânea, especialmente nas atividades ligadas ao turismo (Debbage / Ioannides 2002: 101). ${ }^{11} \mathrm{~A}$ este 
respeito, o antropólogo Greenwood (1977) denuncia explicitamente o tratamento da cultura como mais um recurso turístico - em especial com a promoção do "local color" - e aponta para a posição de fragilidade em que ficam as comunidades, que veem alterada a sua cultura e são, portanto, exploradas: "Under these circumstances, local culture is in effect being expropriated, and local people are being exploited" (1977: 131).

As consequências identitárias deste processo são evidentes: produz-se a perda de referentes que funcionavam para a comunidade como forma de organização social e vital e que agora são submetidos a um processo de mercantilização e desnaturalização. Verifica-se, ainda, a já referida perda da direcionalidade habitual dos discursos turísticos, que já não são apenas consumidos pelos visitantes, mas também pela própria comunidade anfitriã, levando à reconfiguração da sua auto-perceção. ${ }^{12}$ Nesta orientação, deve ser igualmente considerada a participação ativa do turismo nos processos de homogeneização cultural derivados da globalização. Como indica García Canclini: “En una cultura industrializada, que necesita expandir constantemente el consumo, es menor la posibilidad de reservar repertorios exclusivos para minorías" (2001: 98).

\section{Estudar o turismo a partir dos estudos da literatura e da cultura: motivos e caminhos}

A capacidade tentacular e o caráter omnívoro das práticas turísticas promoveram a sua expansão até praticamente qualquer área, tema ou território, incluindo a literatura, como demonstra o apogeu recente do turismo literário, nas suas diversas concretizações. As interseções que, hoje em dia, se produzem entre literatura e cultura e o turismo exigem novas abordagens analíticas e leituras críticas renovadas.

O turismo apresenta dimensões políticas, económicas e culturais e estes aspetos são atendidos de forma parcial por/em cada uma das configurações académicas dedicadas ao seu estudo. No entanto, a institucionalização dos estudos turísticos esteve - e continua a estar - estreitamente vinculada à sua vertente económica, não dialogando suficientemente com os outros aspetos da sua natureza. 0 facto de se tratar de um fenómeno em expansão, 
que está a afetar a produção e difusão cultural, obriga, na minha opinião, a abordar esta prática do ponto de vista das humanidades.

Harald Hendrix (2014: 19) situa em finais da década de 80 do século XX o desenvolvimento do turismo literário e a inícios dos 90 o surgimento do interesse académico pelos cruzamentos entre literatura e turismo. Apesar de este autor assinalar que tal sucede em vários países, a verdade é que a investigação académica sobre este campo está ainda muito centrada no âmbito anglo-saxónico. Muitos destes estudos - alguns exemplos dos quais, principalmente para o caso português, podem ser localizados em Quinteiro e Baleiro (2014) - estão focados em: produtos associados ao turismo literário (museus, casas de autoras/es, rotas, festivais, etc.); no turismo e nas viagens como tema ou motivo; ou, inclusive, no tratamento dos espaços nas obras literárias. É frequente neste olhar a procura - de forma direta ou indireta - de novas criações suscetíveis de serem utilizadas pela indústria turística, como podemos constatar a partir das palavras de Martino Alba (2017: 48):

(...) en nuestro artículo defendemos la idea de que el gestor turístico, con una profunda y arraigada formación humanística, será más imaginativo y creativo a la hora de poner en marcha novedosos productos turísticos basados en los recursos que ofrece la percepción de los autores literarios en sus recorridos viajeros.

Ou, tomando as palavras de Hendrix, que prevê uma revalorização das humanidades em setores políticos e económicos (2014: 21; itálicos meus):

This then also indicates an opening towards the world of enterprise and politics, not only in the professions traditionally linked to the humanities, as museum management is, but also in other sectors where even more capital and political interest is at stake, like for instance regional development, heritage management and the leisure industry. The topic of literature and tourism therefore offers quite some opportunities to connect the world of scholarly analysis with the culture industry at large, and the commercial and political interests underlying it.

Face à grande ênfase que muitos estudos turísticos colocam na figura do visitante, a 
abordagem que defendo procura conhecer as consequências destes processos para as comunidades locais, em diferentes vertentes. Há três elementos interligados que confluem para o interesse de uma proposta analítica articulada sobre as conexões entre cultura e turismo. Em primeiro lugar, a expansão do turismo e a sua relação com as indústrias culturais, em especial com a literatura; ${ }^{13}$ segundo, a construção social e cultural do espaço e o seu progressivo tratamento como objeto de consumo; e, finalmente, o denominado material turn (viragem material) consistente no acentuar da dimensão física das obras de arte, incluindo a literatura, que funcionam, segundo Hendrix (2014: 21), como mediadoras tangíveis entre o mundo físico e o universo da imaginação.

Um dos aspetos que pode ser tratado neste sentido é, por exemplo, o papel dos produtos literários e culturais na construção dos imaginários turísticos. Dado que a produção do espaço turístico é um ponto fundamental para compreender o turismo atual "we have long argued that comprehending tourism requires improved understanding of how the tourism production system manipulates and shapes tourist places and destinations" (Debbage / Ioannides 2002: 99 e s.) -, torna-se oportuno pensar de que modo os referentes culturais são utilizados pela indústria turística, mas também como estes funcionam socialmente fora dos campos artísticos. Assim, Hendrix (2014: 27) explica como a literatura causa um envolvimento emocional muito maior nas audiências do que as outras artes, o que resulta em diferentes formas de apego (embora seja necessário talvez questionar até que ponto isto se mantém na atualidade, à luz de outras modalidades de produtos culturais - como a banda desenhada ou os filmes - e em que medida isto está dependente de processos mediáticos de difusão e comercialização). No entanto, casos como os parques de aventuras inspirados na figura de Harry Potter e que funcionam sobretudo com base nos filmes desta saga, mostram-nos como, por vezes, o referente literário original fica diluído ante o poder de difusão e de fixação/materialização de imaginários que apresentam modalidades culturais de natureza visual e, particularmente, a indústria do cinema.

Outro ponto de interesse analítico pode residir nas leituras atuais sobre a figura do flâneur ou sobre a ideia de alteridade que derivam das tendências observáveis na prática 
turística na contemporaneidade, articulada em torno da observação em movimento do alheio (o outro imaginado e consumido). Para além disso, também as conexões do turismo com o que tradicionalmente foi denominado como literatura ou escrita de viagens constituem um vasto campo de trabalho dentro do quadro de investigação proposto. Existem vários elementos relevantes nesta modalidade de produção, tais como: as dificuldades para a sua definição (ou inclusive a sua consideração - ou não - como género literário independente); o facto de estar dominada pela visão romântica e, em grande medida, eurocêntrica, incluindo o seu papel como instrumento do colonialismo; ou a viagem como enquadramento temporal e espacial de conhecimento e reconhecimento interno e externo, entre muitos outros aspetos que não é possível registar e tratar aqui. No caso concreto da sua relação com o turismo, existem visões opostas sobre a sua categoria e funcionalidades. Mike Robinson (2004) defende a utilidade de incorporar a escrita de viagens aos estudos turísticos e denuncia a ausência de atenção académica sobre ela até o momento (idem: 312):

Future research needs to be bold to take on the intricacies and complexities of travel writing-tourism relationships. Closer examination of the relationships that exist between travel writing and the production/consumption of tourist space, and between narratives of travel and the motivations/experiences/performances of tourists should be central to an emergent research agenda in tourism studies.

Contrariamente a Robinson, Hendrix (2014) estabelece diferenças entre o que considera a "literatura de turismo"14 e a "literatura de viagens", optando por uma visão mais restrita para o estabelecimento de uma vinculação entre elas. Nas suas palavras (idem: 22):

(...) I would be hesitant to include all travel writing within our specific field of literature and tourism. To my mind such a connection exists only in a few particular cases, where on the one hand authorship can be explicitly linked to tourist practices, and where on the other hand the literary representation of space adds to its value as a tourist attraction.

Uma outra linha de trabalho suscetível de ser percorrida conecta a construção do 
cânone literário, a circulação internacional da cultura e os imaginários nacionais. Os materiais turísticos (do quais os guias seriam o formato mais representativo mas não o único) são conservadores na sua natureza, isto é, divulgam ideias já consolidadas socialmente, o que os torna potenciais indicadores ou referências para avaliar certos processos. A este respeito, é interessante reparar na posição atribuída neles à cultura e especificamente à literatura, assim como à seleção de nomes oferecida e os motivos para realizá-la, sem esquecer as variações temporais que esta experimenta. Caberia questionarnos, portanto, se os materiais turísticos reproduzem apenas o cânone literário ou podem contribuir, de certa forma, para a sua construção. ${ }^{15}$

Em geral, observamos que, nos guias turísticos, é atribuída uma posição secundária à literatura face a outras práticas artísticas de natureza visual, e deparamos com uma visão estereotipada e muito simplificadora da realidade, principalmente nos materiais destinados a público estrangeiro. Por exemplo, no contexto português, durante muito tempo e até à década de 90 do século XX, Luís de Camões era praticamente o único escritor referido nos materiais turísticos. Cabe questionar em que medida a consagração internacional de Fernando Pessoa ou o prémio Nobel atribuído a José Saramago contribuíram para relocalizar a posição atribuída ao autor de Os Lusíadas nos materiais turísticos recentes. Como é lógico, estas (re)configurações apresentam fortes associações com a imagem projetada - ou que se pretende/consegue projetar - de Portugal no exterior, sem esquecer que não são só os poderes políticos (nacionais) os emissores deste tipo de discursos. Para já, é identificável nos souvenirs atuais relativos à cidade de Lisboa a ausência da figura de Camões e o predomínio de Pessoa, por se tratar de um referente mais afim e reconhecível para as sensibilidades e gostos do presente, representando a modernidade (também da cidade) e inclusive certos conflitos existenciais contemporâneos (embora mediados pelo tom lúdico que impera no turismo).

\section{Conclusões e perguntas para o futuro}

As conclusões deste artigo configuram-se simultaneamente como perguntas e desafios relativos ao estudo futuro dos cruzamentos entre literatura/cultura e turismo, 
para o qual deve ser procurado um quadro analítico próprio mas em dívida e diálogo com disciplinas confluentes como a antropologia, a sociologia ou a geografia cultural. 0 interesse dos avanços realizados nestas áreas não se esgotam nas referências reunidas neste trabalho, da mesma forma que as vias de análise a explorar sobre o turismo e os estudos da literatura e da cultura aqui esboçadas podem (e devem) ser completadas e ampliadas.

A progressiva expansão do turismo cultural como modalidade diferenciada e supostamente mais benévola do que o turismo de massas, e onde o turismo literário é uma área em emergência, deveria alertar-nos para a necessidade de tratar criticamente este fenómeno, tendo, aliás, em consideração as dinâmicas negativas geradas à volta do turismo, com processos de exclusão material e simbólica e o acentuar da estratificação social, como é possível ver nos processos de gentrificação ativos em diferentes urbes (e não só) contemporâneas, entre elas, o Porto e Lisboa.

Num ensaio sobre a famosa coleção francesa Les Guides Bleus (concretamente um volume sobre a Espanha), Roland Barthes denunciava a ideologia burguesa ali presente por anular as realidades humanas, quase sempre decorativas e apresentadas sob um olhar essencialista, face à relevância atribuída aos monumentos (1957: 114; itálicos no original, negrito meu):

De même que la montuosité est flattée au point d'anéantir les autres sortes d'horizons, de même l'humanité du pays disparaît au profit exclusif de ses monuments. Pour le Guide bleu, les hommes n'existent que comme "types". En Espagne, par exemple, le Basque est un marin aventureux, le Levantin un gai jardinier, le Catalan un habile commerçant et le Cantabre un montagnard sentimental. On retrouve ici ce virus de l'essence, qui est au fond de toute mythologie bourgeoise de l'homme (ce pour quoi nous la rencontrons si souvent). L'ethnie hispanique est ainsi réduite à un vaste ballet classique, une sorte de commedia dell'arte fort sage, dont la typologie improbable sert à masquer le spectacle réel des conditions, des classes et des métiers. Socialement, pour le Guide bleu, les hommes n'existent que dans les trains, où ils peuplent une troisième classe “mélangée". Pour le reste, ils ne sont qu'introductifs, ils composent un gracieux décor romanesque, destiné à circonvenir l'essentiel du pays : sa collection de monuments. ${ }^{16}$

Apesar de apresentados como documentos neutros, os guias e os materiais turísticos 
são relatos social e ideologicamente marcados. Em geral, o turismo é retrógrado e incentiva discursos próximos ao nacionalismo (numa orientação hegemónica e conservadora), ao classismo ou ao sexismo, além de estar fortemente associado a uma ideia romântica do passado. É pertinente reparar na força uniformizadora que deriva deste fenómeno, estruturado em torno a mensagens muito simplificadas e pretensamente acessíveis a todos os públicos. Estes discursos estão, aliás, dominados por uma certa ética do prazer, própria das práticas turísticas, que anula ou relativiza os ângulos escuros, o que provoca o habitual desaparecimento de qualquer elemento problemático ou o seu tratamento de forma banal. ${ }^{17}$

Nesta linha, uma das chaves mais recorrentes nos discursos turísticos é a sua dimensão de representatividade nacional num contexto de globalização. Uma representação quase sempre simplificadora e estereotipada, vinculada precisamente à ideia do cânone, e que contrasta com uma certa emergência no campo académico dos discursos pós-nacionais. Bauman (1998: 63) alude precisamente a como, ante a crise dos estados-nação e a sua falta de impacto político-económico no mundo atual, surge a necessidade por parte da nação de manter e projetar a sua dimensão cultural como sustentador da sua identidade. Deste ponto de vista, o turismo funciona também como elemento coesivo das identidades nacionais (tanto através das auto-imagens como das hetero-imagens) num espaço de trocas materiais e simbólicas cada vez mais articulado a um nível transnacional.

Historicamente houve uma demora na incorporação do turismo como objeto de análise nos estudos sociais críticos face à ingerência da indústria e dos poderes políticos na agenda investigadora sobre este elemento (Hall et al 2004: 14), com as consequências na produção de conhecimento que daí derivaram/derivam. Os desafios que acabo de lançar denotam a necessidade de abordagens sobre este fenómeno desenhadas a partir dos estudos literários e da cultura que incorporem a sua bagagem crítica e metodológica, introduzindo metodologias inovadoras que permitam a apreensão deste objeto de estudo em expansão. Propomos, portanto, uma ação simbiótica que visa tanto a modificação das leituras e da compreensão sobre as práticas turísticas, como a introdução de novos métodos e prismas nos estudos da literatura e da cultura. 


\section{NOTAS}

1 Agradeço as recomendações linguísticas que muito amavelmente realizou a Professora Doutora Sílvia Quinteiro para este artigo. Contudo, as escolhas finais são da minha exclusiva responsabilidade, algumas das quais ligadas a uma variedade galega da língua portuguesa e ao desejo de promover a igualdade, também linguística, entre os géneros.

${ }^{2}$ Em palavras do sociólogo do turismo John Urry: "Tourism always involves corporeal movement and forms of pleasure and these must be central in any sociology of diverse tourisms. In that sense the tourist gaze always involves relations between bodies that are themselves in at least intermittent movement" (Urry 2002: 152).

${ }^{3}$ Urry aprofunda estes conceitos e reflete sobre eles em vários pontos da sua obra The Tourist Gaze; veja-se, por exemplo, Urry (2002: 42 e ss.). Por outro lado e entre os argumentos por ele colocados, são relevantes as diferenças nas sociabilidades, ou inclusive nos discursos e usos projetados, articuladas com base nestas duas modalidades de fazer turismo (Urry 2002: 150):

Moreover, these different discourses imply different socialities. With what (...) I call the romantic gaze, solitude, privacy and a personal, semi-spiritual relationship with the object of the gaze are emphasised. In such cases tourists expect to look at the object privately or at least only with 'significant others' (...). Notions of the romantic gaze are endlessly used in marketing and advertising tourist sites especially within the 'west'. By contrast what I call the collective tourist gaze involves conviviality. Other people also viewing the site are necessary to give liveliness or a sense of carnival or movement. Large numbers of people that are present can indicate that this is the place to be. These moving, viewing others are obligatory for the collective consumption of place (...).

${ }^{4}$ Estas questões são tratadas e sintetizadas por Hall, Williams e Lew (2004: 4 e ss.).

5 Desde o trabalho de MacCannel (1999 [1976]), foram muitos os estudos sobre turismo que abordaram o tema da autenticidade e as mudanças experimentadas nas expetativas sobre este elemento. Veja-se, por exemplo, Wang (1999).

${ }^{6} \mathrm{O}$ antropólogo Xerardo Pereiro (2009: 57) reflete sobre a criação dos imaginários turísticos e o recurso a fórmulas cliché que incidem no encanto ou na descoberta dos lugares e que podem dar origem a uma "imagem que se converte em profílmica e estática de uma realidade mais complexa. Esta imagem distorcida pode chegar mesmo a substituir a realidade pela hiper-realidade".

7 MacCannel (1999) estudou precisamente os processos de construção da atração turística sobre um determinado elemento através de uma leitura semiótica estruturada em torno da relação entre "markers" e "sights" (1999: 109 e ss.). Nesta linha, veja-se também Culler (1981).

${ }^{8} \mathrm{Na}$ análise desenvolvida por Anselm Jappe (2008 [1993]) sobre a obra de Debord, define o espetáculo como a "forma mais desenvolvida da sociedade baseada na produção de mercadorias e no 'fetichismo da mercadoria' 
que daí decorre" (idem: 13). 0 espetáculo funciona como elemento alienante, assentado no isolamento das pessoas e na monopolização da comunicação, de modo que "a actividade social inteira é captada pelo espectáculo para servir os seus próprios fins. (...) E, neste processo, a imagem acaba por se tornar real, sendo causa de um comportamento real, e a realidade acaba por se tornar imagem" (idem: 18). Novamente encontramos conexões com algumas das propostas já enunciadas sobre o conflito entre realidade e ficção ou com a ideia da hiper-realidade.

${ }^{9}$ Manuel Delgado (2007: 96) define a tematização como a:

(...) reducción a la unidad de que una determinada realidad puede ser objeto, con el fin de reducir sus índices de complejidad y orientar su percepción en un sentido homogéneo y compartible. Ni qué decir tiene que tematización no es sólo sometimiento de la vida social a una simplicidad representacional inspirada en lugares comunes que son permanentemente enfatizados, sino también monitorización, es decir control a distancia de las conductas que en tales escenarios deben desarrollarse.

${ }^{10}$ Crang (2002) propõe uma leitura renovada das "tourist cultures" (2002: 74), partindo da ideia do "tourism as inventing, making, and remaking places" (2002: 75). Neste sentido, têm lugar fenómenos complexos que implicam a modificação da cultura local, mas sem uma leitura plana e unicamente centrada na denúncia da homogeneização derivada deste processo. As práticas turísticas produzem, em definitivo e de forma recorrente, destinos e visitantes (Crang 2002: 83). Por outro lado, García Canclini (2001: 14) propõe a seguinte definição da hibridação: "procesos socio-culturales en los que estructuras o prácticas discretas, que existían en forma separada, se combinan para generar nuevas estructuras, objetos y prácticas".

11 García Canclini (2001) reflete sobre a apropriação mercantil que se produz sobre elementos da cultura popular, particularmente o artesanato e a música tradicional, que passam a fazer parte dos "circuitos masivos transnacionales, donde los productos populares suelen ser 'expropiados' por empresas turísticas y comunicacionales" (2001: 23).

${ }^{12}$ A respeito da assunção pelos locais dos imaginários turísticos construídos sobre eles, Xerardo Pereiro (2009: 56) afirma que: "muitas vezes as comunidades locais se apropriam e assimilam a imagem projectada a partir do exterior da mesma, ainda que este processo não esteja isento de tensões, rejeições e negociações". É também interessante reparar na reconfiguração das identidades que deriva dos fluxos culturais da contemporaneidade e que García Canclini coloca deste modo: "La transnacionalización de la cultura efectuada por las tecnologías comunicacionales, su alcance y eficacia, se aprecian mejor como parte de la recomposición de las culturas urbanas, junto a las migraciones y el turismo de masas que ablandan las fronteras nacionales y redefinen los conceptos de nación, pueblo e identidad" (2001: 45; itálicos meus). 
13 O próprio Hendrix (2014: 19) constata a expansão deste sector nalguns países, como em França, e indica que: "This considerable expansion of the literary heritage tourist industry has generated a parallel growth of professional organisations and training institutions linked to this very industry".

${ }^{14}$ A fórmula original "tourist literature" foi traduzida por Quinteiro e Baleiro (2017: 21 e ss., especialmente idem: 24) como "literatura de turismo", que definem como: "conjunto de textos, que por determinados efeitos intencionais e semânticos (...), são permeáveis a uma exegese interdisciplinar nas áreas da literatura e do turismo" (idem: 21). Estas investigadoras oferecem, aliás, com esta noção, uma alternativa para a tensão aqui esboçada entre "literatura de turismo" e "literatura de viagens".

${ }^{15}$ Embora esta afirmação possa parecer contraditória em relação à reflexão prévia sobre o conservadorismo, é necessário ter em conta a diversidade dos guias e materiais turísticos existentes, assim como os diferentes tempos de atuação, autoria, público-alvo e funções. Deste modo, existem propostas que aprofundam de forma mais direta na literatura ou na cultura, contemplando também a época presente, e que podem propiciar a fixação e reconhecimento de autoras/es. No entanto, esta função é habitualmente complementar, sendo mais que provável uma certa consolidação prévia dos nomes selecionados no campo literário de origem.

${ }^{16} \mathrm{E}$, ainda, umas páginas à frente, afirma: "Le Guide bleu, lui, en est resté à une mythologie bourgeoise partiellement périmée, celle qui postulait l'Art (religieux) comme valeur fondamentale de la culture, mais ne considérait ses 'richesses' et ses 'trésors' que comme un emmagasinement réconfortant de marchandises (création des musées)" (Barthes 1957: 116).

17 Esta tendência é também observável nalguns estudos sobre o turismo interessados em enfatizar os benefícios económicos e onde os custos sociais ou ambientais são ignorados. Talvez esta afirmação possa ser reexaminada para casos como o dark tourism, porém, a sua própria consolidação como modalidade turística evidencia a relativização e afastamento dos factos trágicos originários. 


\section{Bibliografia}

Augé, Marc (1998), El viaje imposible. El turismo y sus imágenes [1997], trad. Alberto Luis Bixio, Barcelona, Gedisa.

Barthes, Roland (1957), Mythologies, Paris, Éditions du Seuil.

Baudrillard, Jean (1981), Simulacres et simulation, Paris, Galilée.

Bauman, Zymunt (1998), Globalization. The Human Consequences. Cambridge, Polity Press.

-- (2000), Liquid Modernity, Oxford, Blackwell.

Bourdieu, Pierre (1979), La Distinction. Critique sociale du jugement, Paris, Minuit.

-- (1992), Les règles de l'art, Genèse et structure du champ littéraire, Paris, Éditions du Seuil.

Crang, Mike (2004), "Cultural Geographies of Tourism", in A Companion to Tourism, Alan A.

Lew / C. Michael Hall / Allan M. Williams (eds.), Oxford, Blackwell, 74-84.

Crouch, David (2002), "Tourist Practices and Performances", in A Companion to Tourism, Alan A. Lew / C. Michael Hall / Allan M. Williams (eds.), Oxford, Blackwell, 85-95.

Culler, Jonathan (1981), "Semiotics of Tourism”, American Journal of Semiotics 1, 127-40.

d'Hauteserre, Anne-Marie (2004), "Postcolonialism, colonialism, and tourism", in A Companion to Tourism, Alan A. Lew / C. Michael Hall / Allan M. Williams (eds.), Oxford, Blackwell, 235-245.

Debbage, Keith G. / Dimitri Ioannides (2002), “The Cultural Turn? Toward a More Critical Economic Geography of Tourism", in A Companion to Tourism, Alan A. Lew / C. Michael Hall / Allan M. Williams (eds.), Oxford, Blackwell, 99-109.

Debord, Guy (1992), La societé du spectacle, Paris, Gallimard [1967].

Delgado, Manuel (2007), “Ciudades sin ciudad. La tematización 'cultural' de los centros urbanos", in Antropología y turismo. Claves culturales y disciplinares, David Lagunas 
(coord.), México, Plaza y Valdés, 91-108.

Eco, Umberto (1986), Faith in Fakes: Essays, trad. William Weaver, Londres, Secker and Warburg.

García Canclini, Néstor (2001), Culturas híbridas. Estrategias para entrar y salir de la modernidad, Buenos Aires, Paidós [1989].

Greenwood, Davydd J. (1977), "Culture by the Pound: an Anthropological Perspective on Tourism as Cultural Commoditization", in Hosts and Guests: the Anthropology of Tourism, Valene L. Smith (ed.), Oxford, Blackwell, 129-138.

Hall, C. Michael / Hazel Tucker (eds.) (2005), Tourism and Postcolonialism: Contested Discourses, Identities and Representations, London \&New York, Routledge.

Hall, C. Michael / Allan M. Williams / Alan A. Lew (2004), "Tourism: Conceptualizations, Institutions, and Issues", in A Companion to Tourism, Alan A. Lew / C. Michael Hall / Allan M. Williams (eds.), Oxford, Blackwell, 3-21.

Hendrix, Harald (2014), "Literature and Tourism: Explorations, Reflections, and Challenges", in Sílvia Quinteiro e Rita Baleiro (orgs.), Lit\&Tour. Ensaios sobre literatura e turismo, Vila Nova de Famalicão, Humus, 19-29.

Jappe, Anselm (2008), Guy Debord, trad. Iraci D. Poleti e Carla da Silva Pereira, Lisboa, Antígona [1993].

MacCannel, Dean (1999), The Tourist. A New Theory of the Leisure Class, Berkeley, Los Angeles, University of California Press [1976].

Martino Alba, Pilar (2017), "La literatura como recurso cultural para la creación de nuevos productos turísticos", Methaodos. Revista de ciencias sociales 5 (1): 48-61. <http://dx.doi.org/10.17502/m.rcs.v5i1.147> (último acesso em 05/09/2017).

Pereiro, Xerardo (2009), Turismo cultural. Uma visão antropológica, Tenerife, Pasos.

Quinteiro, Sílvia / Rita Baleiro (orgs.) (2014), Lit\&Tour. Ensaios sobre literatura e turismo, Vila Nova de Famalicão, Humus. 
-- (2017), Estudos em literatura e turismo: Conceitos fundamentais, Lisboa, Centro de Estudos Comparatistas.

Robison, Mike (2004), "Narratives of Being Elsewhere: Tourism and Travel Writing", in $A$ Companion to Tourism, Alan A. Lew / C. Michael Hall / Allan M. Williams (eds.), Oxford, Blackwell, 303-315.

Smith, Stephen L.J. (2004), "The Measurement of Global Tourism: Old Debates, New Consensus, and Continuing Challenges", in A Companion to Tourism, Alan A. Lew / C. Michael Hall / Allan M. Williams (eds.), Oxford, Blackwell, 25-35.

Urry, John (2002), The Tourist Gaze. Leisure and Travel in Contemporary Societies, segunda edição, London, Sage.

Wang, Ning (1999), "Rethinking authenticity in tourism experience", Annals of Tourism Research 26(2), 349-70.

Cristina Martínez Tejero é investigadora de pós-doutoramento no Centro de Estudos Comparatistas (CEC) da Universidade de Lisboa, onde faz parte do grupo LOCUS (Espaço, lugares e paisagens) e dos projetos Lit\&Tour (Literatura e Turismo), CILM (Cidade e (in)segurança na literatura e os média) e DIIA (Diálogos Ibéricos e Ibero-americanos). Integra também o grupo Galabra (Grupo de pesquisa no sistemas galego, luso, brasileiro e africanos de língua portuguesa) e o CIPPCE (Centro de investigación de procesos e prácticas culturais emerxentes), ambos pertencentes à Universidade de Santiago de Compostela. Os seus atuais interesses de investigação conectam a cultura, o espaço, a globalização e o turismo. 